\title{
Study on Large-Scale Promotion of Prefabricated Buildings in Anhui Province Based on SEM and IoT
}

\author{
Weishu Zhao (i) and Yuting Chen (i) \\ School of Economics and Management, Anhui Jianzhu University, Hefei 230601, Anhui, China \\ Correspondence should be addressed to Yuting Chen; cytdiu@163.com
}

Received 8 December 2021; Revised 23 December 2021; Accepted 3 January 2022; Published 18 January 2022

Academic Editor: M. Pallikonda Rajasekaran

Copyright (c) 2022 Weishu Zhao and Yuting Chen. This is an open access article distributed under the Creative Commons Attribution License, which permits unrestricted use, distribution, and reproduction in any medium, provided the original work is properly cited.

\begin{abstract}
The development of prefabricated buildings is an important measure to implement and promote supply-side structural reforms in order to better promote the development of assembly construction scale in Anhui province. This is also needed for the transformation and upgradation of the construction industry. On the basis of literature analyses, expert interviews, and questionnaire surveys, this paper analyzes the key factors affecting the large-scale promotion of prefabricated buildings in Anhui province from five dimensions by using a structural equation model. These key factors are policy support, market circumstances, public awareness, economic cost, and technical support. The results show that policy support and technical support factors have a greater impact on the large-scale development of prefabricated buildings. We should strengthen the supervision mechanism and build the assembly building management system combining the BIM, Internet of things, and other technologies. According to the research results, we put forward corresponding countermeasures and suggestions to provide a reference for the large-scale development of prefabricated buildings in Anhui province.
\end{abstract}

\section{Introduction}

Prefabricated building is based on the mode of prefabricated production of component factories and onsite assembly installation. It is characterized by standardized design, factory production, assembly construction, integrated decoration, and information management. It integrates research and development design, manufacturing, and onsite assembly. In various business areas, we will realize a new sustainable construction production method that maximizes energy conservation, environmental protection, and the fullcycle value of building products. Vigorously developing prefabricated buildings is the requirement of the development of China's construction industry under the background of the new era and is also the main way to realize the transformation and upgradation of traditional construction methods. Promoting the development of prefabricated buildings in Anhui province plays an important role in the green development and supply-side reform of Anhui province. It is also conducive to the stable development of
China's economy, by realizing technological upgrading, by improving production efficiency, by guaranteeing the quality of housing, and by realizing the green development of buildings [1]. The prefabricated building has different industrial foundations and development statuses in different regions. According to different regions to adopt different prefabricated building development paths, adjust measures according to local conditions so as to actively and effectively promote the development of prefabricated building in Anhui province.

Taking economy, ecology, society, and safety as dimensions and from the perspective of the whole life cycle, Pang [2] studied the cost of prefabricated buildings and established an analytical model using AHP. He found that the professional level in technical factors was the main factor affecting the cost of prefabricated buildings. Mao [3] took a prefabricated building demonstration project in Fujian Province as an example and found that prefabricated building costs were mainly affected by PC component costs and onsite installation costs. He proposed countermeasures 
to control prefabricated building costs from three aspects of enterprises, industries, and policies. According to the lifecycle cost theory, Dong [4] constructed a monetization calculation model for the life-cycle economic and environmental benefits of prefabricated buildings. Through the case study, he found that the cost-benefit evaluation of prefabricated buildings was feasible only on the premise of the comprehensive analysis of economic and environmental benefits. Wang [5] studied the risk factors affecting the cost of prefabricated buildings from the perspective of the whole life cycle and made a comprehensive evaluation of the cost risk factors. On this basis, he put forward measures to deal with risks, providing some reference for the cost management of prefabricated buildings. Shen et al. [6] used lean cost management theory to analyze the cost composition of prefabricated buildings. Specific management measures were put forward according to the cost difference of each implementation stage of the assembly building. It provided reference value for reducing the construction cost of the assembly building. Based on the lean theory, Zhou [7] analyzed the design, production, transportation, and installation costs of prefabricated buildings from the perspective of the value stream. Through structural matrix and cluster calculation, he believed that information integration in the construction process of prefabricated buildings had a great impact on the cost. Wang et al. [8] analyzed the causes of incremental costs by comparing the incremental costs of prefabricated buildings and traditional buildings, and he proposed specific measures to reduce incremental costs. Cui [9] adopted principal component analysis to analyze the factors affecting the cost of prefabricated construction, and he put forward measures and suggestions to reduce costs from the perspectives of policy, standard system, and industry system.

Barlow et al. [10] believed that information technology could significantly reduce construction costs through the allaround application of information technology in the industrial construction of housing. Bortolini et al. [11] believed that the synergy of the BIM model could solve the complex problem of component scheduling. Hong et al. [12] considered the benefits of prefabricated buildings and established a cost analysis framework to analyze practical cases and put forward countermeasures. The existing research results did not systematically and comprehensively consider the coupling effect between the precast parts and the working spaces. The conclusion was that the construction cost of the prefabricated building was difficult to control effectively. Lopez [13] made a comparative analysis of the cost of two assembly schemes of prefabricated housing, providing guidance for the selection of prefabricated housing schemes. Based on BIM technology, Johnston et al. [14] constructed a BIM model of the prefabricated building to simulate the construction process of the prefabricated building, and further reduced the construction cost of prefabricated buildings by improving the construction schedule. Under the guidance of lean construction theory, Fard et al. [15] analyzed the safety risks in the production and onsite assembly of prefabricated building components from the perspective of manufacturing enterprises. This improved the level of construction safety for prefabricated buildings. Arashpour et al. [16] argued that the production, supply, and cost of prefabricated components were mainly influenced by supply decisions. The influence of single supplier cooperation and multisupplier cooperation on procurement was analyzed quantitatively. This provided a theoretical basis for the production and supply of prefabricated components.

In view of this, this paper takes Anhui Province as the research object, constructs a structural equation model, and considers the coupling relationship among five dimensions of prefabricated building policy support, market circumstances, propaganda cognitive, economic cost, and technical support. Finally, the paper analyzes the key factors affecting the large-scale increase of assembly construction cost in Anhui province and puts forward corresponding countermeasures. This puts forward scientific and reasonable solutions and suggestions for better promoting the development of assembly buildings in Anhui province.

\section{Index of Influencing Factors for Large-Scale Promotion of Prefabricated Buildings}

In order to scientifically and systematically select the factors affecting the large-scale promotion of prefabricated buildings in Anhui Province, an objective and fair evaluation system was established for the large-scale promotion of prefabricated buildings. This paper selects and evaluates the influencing factors on the basis of the research on the large-scale promotion of prefabricated buildings by relevant scholars. The expert interview method is used to further extract and analyze the influencing factors identified initially. This paper tries to make the obtained factors of large-scale promotion of prefabricated buildings match with the actual environment to ensure its rationality, so as to determine the primary and secondary indicators affecting the large-scale promotion of prefabricated buildings. In addition, the exploratory factor analysis and principal component analysis are conducted to correct the influencing factors.

2.1. Selection of Key Factors. The effective identification and determination of the influencing factors for the large-scale promotion of prefabricated buildings is an important prerequisite for establishing the influencing factor system scientifically and systematically. Based on 223 literatures published on the theme of "large-scale promotion of prefabricated buildings" on CNKI from 2015 to 2020, 105 literatures are selected and identified for statistical analysis of influencing factors. In addition, the results of interviews with experts, teachers, and project managers with years of practical experience in relevant research directions are combined. We obtain 32 factors influencing the large-scale promotion of prefabricated buildings. The influencing factors are summarized as shown in Table 1.

2.2. Questionnaire Design. The system of influencing factors for the large-scale promotion of prefabricated buildings constructed in Table 1 is used as the basis for the 
TABLE 1: Statistical table of influencing factors of large-scale promotion of prefabricated buildings.

\begin{tabular}{|c|c|}
\hline Serial number & Influence factor \\
\hline 1 & Consumer acceptance \\
\hline 2 & Market recognition \\
\hline 3 & The standard level of prefabricated building design and construction \\
\hline 4 & Technical standard specification for prefabricated buildings \\
\hline 5 & Integration degree of key technology system of prefabricated building \\
\hline 6 & Regional economic level \\
\hline 7 & The cost of production \\
\hline 8 & Transportation of components \\
\hline 9 & Assembly costs \\
\hline 10 & Land policy \\
\hline 11 & Prefabricated building production standard system \\
\hline 12 & Prefabricated construction industry acceptance standard \\
\hline 13 & Consumer buying intention \\
\hline 14 & Developer's development intention \\
\hline 15 & Industrial support intensity \\
\hline 16 & Prefabricated building pilot project demonstration effect \\
\hline 17 & The cognition and willingness of each participant \\
\hline 18 & Technical personnel allocation and training \\
\hline 19 & Level of informatization application \\
\hline 20 & Prefabricated construction investment \\
\hline 21 & Fiscal subsidy \\
\hline 22 & Information sharing platform construction \\
\hline 23 & Prefabricated building supervision mechanism \\
\hline 24 & Assembly building supporting industrial chain \\
\hline 25 & Market access system for prefabricated buildings \\
\hline 26 & Prefabricated building promotion \\
\hline 27 & Technology innovation \\
\hline 28 & Collaborative management of prefabricated buildings \\
\hline 29 & Potential benefits \\
\hline 30 & Prefabricated building industry planning \\
\hline 31 & Risk sharing mechanism \\
\hline 32 & Logistics and transportation system \\
\hline
\end{tabular}

construction of the structural equation model, and the questionnaire survey is designed on this basis. The questionnaire adopted the form of a 5-level Likert scale to set the options and scored the influence degree of each factor. The score ranges from 1 to 5 . And with the increase of the score, the importance increases step by step. The questionnaire was sent to experts, scholars, university researchers, and green building practitioners in the professional field by e-mail. In order to ensure the reliability and suitability of the questionnaire, the distribution scope basically covers green building practitioners of different units and different age levels. A total of 300 questionnaires were sent out and 258 were recovered with an effective recovery of $86 \%$. The overall distribution of the questionnaire sample was reasonable and conforms to the actual distribution of the construction. The details are shown in Table 2 .

2.3. Principal Component Analysis. SPSS 22.0 software was used for principal component analysis in this paper to extract common factors and obtain corresponding principal component analysis data. As shown in Table 3 and Figure 1, the eigenvalues of the first five principal components are all greater than 1 and the cumulative contribution rate of the factor is $63.742 \%$. This means that the first five principal components explain most of the information about this variable. Therefore, five principal components are extracted in this paper.

2.4. Rotation Factor Matrix. The component matrix was rotated using SPSS 22.0 software and Kaiser standardized maximum variance method, and the factor whose load value was greater than 0.5 of the original variable explained by the common factor was extracted as the effective factor. According to the above principles, the original variable corresponding to the common factor was extracted. Finally, 21 influence factors were obtained. Variables that meet the requirements are shown in Table 4 rotation factor matrix.

In the rotated factor load matrix, the outputs are arranged according to the descending order of factor load values. The definition and practical characteristics of prefabricated buildings in large-scale promotion research are comprehensively analyzed. The common factors are named and explained and the important influencing factor indicators are obtained. The specific analysis of each dimension is as follows:

The first common factor mainly includes consumers' purchase intention, developers' development intention, industrial support intensity, and assembly building supporting 
TABLE 2: Basic information of respondents.

\begin{tabular}{lccc}
\hline Name & Category & Sample number & Percentage \% \\
\hline \multirow{2}{*}{ Gender } & Male & 157 & 60.85 \\
& Female & 101 & 39.15 \\
\hline \multirow{2}{*}{ Age } & 25 to 30 & 118 & 21.32 \\
& 30 to 40 & 68 & 45.74 \\
& 40 to 50 & 17 & 26.36 \\
Unit attribute & 50 and above & 55 & 21.32 \\
& The construction unit & 84 & 32.56 \\
& Construction unit & 37 & \\
& Design unit & 42 & \\
Working time & Consulting unit & 40 & 14.34 \\
& Research institution & 42 & 16.28 \\
& The following 2 years & 83 & 15.50 \\
\hline
\end{tabular}

TABle 3: Total variance explained.

\begin{tabular}{|c|c|c|c|c|c|c|}
\hline \multirow{2}{*}{ Component } & \multicolumn{3}{|c|}{ Initial eigenvalues } & \multicolumn{3}{|c|}{ Extraction sums of squared loadings } \\
\hline & Total & $\%$ of variance & Cumulative \% & Total & $\%$ of variance & Cumulative $\%$ \\
\hline 1 & 7.875 & 37.501 & 37.501 & 7.875 & 37.501 & 37.501 \\
\hline 2 & 1.653 & 7.870 & 45.371 & 1.653 & 7.870 & 45.371 \\
\hline 3 & 1.476 & 7.030 & 52.401 & 1.476 & 7.030 & 52.401 \\
\hline 4 & 1.340 & 6.379 & 58.780 & 1.340 & 6.379 & 58.780 \\
\hline 5 & 1.042 & 4.962 & 63.742 & 1.042 & 4.962 & 63.742 \\
\hline 6 & 0.797 & 3.797 & 67.540 & & & \\
\hline 7 & 0.708 & 3.373 & 70.913 & & & \\
\hline 8 & 0.653 & 3.110 & 74.022 & & & \\
\hline 9 & 0.609 & 2.899 & 76.921 & & & \\
\hline 10 & 0.580 & 2.760 & 79.681 & & & \\
\hline 11 & 0.555 & 2.641 & 82.322 & & & \\
\hline 12 & 0.501 & 2.385 & 84.706 & & & \\
\hline 13 & 0.463 & 2.204 & 86.911 & & & \\
\hline 14 & 0.441 & 2.101 & 89.012 & & & \\
\hline 15 & 0.417 & 1.983 & 90.996 & & & \\
\hline 16 & 0.365 & 1.736 & 92.732 & & & \\
\hline 17 & 0.360 & 1.716 & 94.447 & & & \\
\hline 18 & 0.351 & 1.672 & 96.119 & & & \\
\hline 19 & 0.314 & 1.495 & 97.615 & & & \\
\hline 20 & 0.264 & 1.257 & 98.872 & & & \\
\hline 21 & 0.237 & 1.128 & 100.000 & & & \\
\hline
\end{tabular}

Extraction method: principal component analysis.

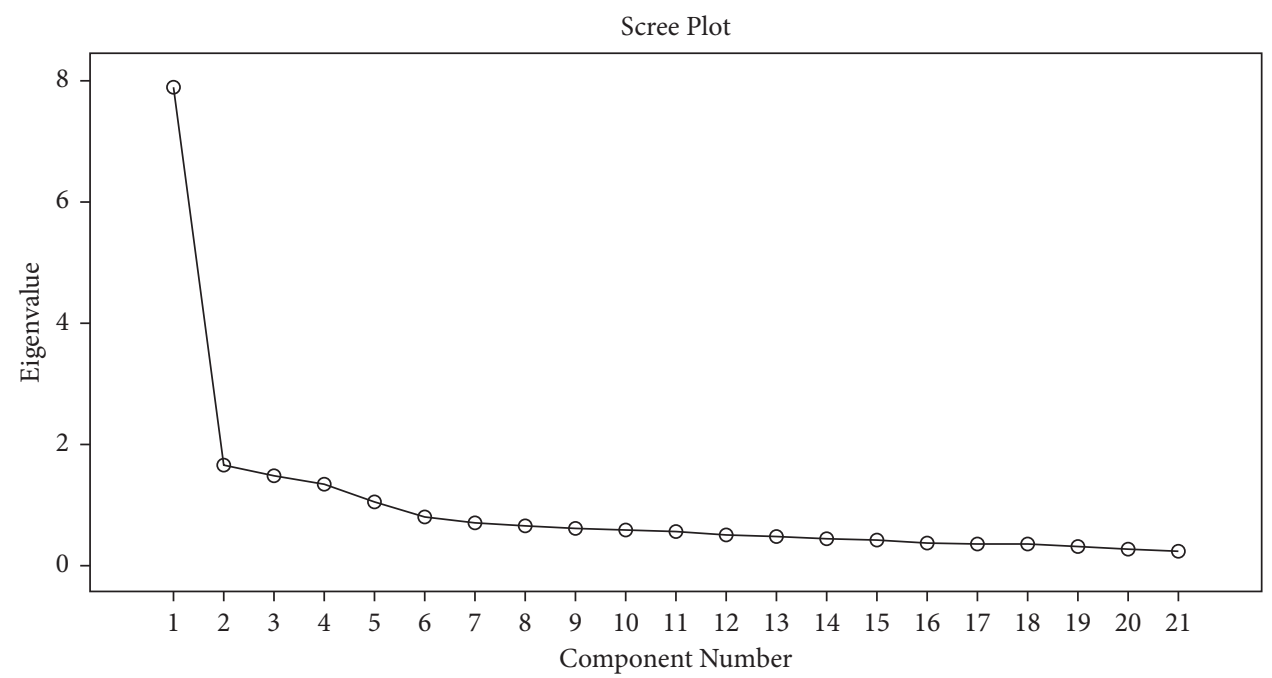

Figure 1: Gravel figure. 
TABLE 4: Rotated component matrix ${ }^{\mathrm{a}}$.

\begin{tabular}{lcc}
\hline & 1 & Component \\
& 2 & 3 \\
\hline Consumer buying intention & 0.823 & 4 \\
Developer's development intention & 0.769 & 0.769 \\
Industrial support intensity & 0.691 & 0.727 \\
Assembly building supporting industrial chain & 0.719 \\
Information sharing platform construction & 0.672 \\
Prefabricated building supervision mechanism & 0.599 \\
Prefabricated building production standard system & 0.555 \\
Prefabricated building industry planning & 0.832 \\
Prefabricated construction industry acceptance standard & 0.779 \\
Market recognition & 0.740 \\
Prefabricated building promotion & 0.657 \\
Prefabricated building pilot project demonstration effect & \\
Participants' awareness of prefabricated buildings and willingness to collaborate & \\
Integration degree of key technology system of prefabricated building & 0.736 \\
Technical personnel allocation and training & 0.736 \\
The standard level of prefabricated building design and construction & 0.735 \\
Technology innovation & \\
Financial subsidies or preferential tax support & 0.507 \\
Regional economic level & \\
Construction costs of prefabricated buildings & \\
Prefabricated construction investment & \\
\hline
\end{tabular}

Extraction method: principal component analysis. Rotation method: varimax with Kaiser normalization.

industry chain. Due to the low participation of relevant stakeholders in the assembly building industry, the supporting industry chain is not yet mature, and the market environment of the assembly building is not yet sound. Therefore, this kind of factor is called the market environment influence factor.

The second common factor mainly includes information sharing platform construction, prefabricated building supervision mechanism, prefabricated building production standard system, prefabricated building industry planning, and prefabricated building industry acceptance standard. All these factors reflect the government's guidance and support for prefabricated buildings. Therefore, these factors are called policy support impact factors.

The third common factor mainly includes market recognition degree, prefabricated building publicity and promotion, prefabricated building pilot project demonstration effect, and the cognition degree and cooperation willingness of each participant. These factors reflect the publicity and public awareness of prefabricated buildings. Then, these factors are called propaganda cognitive influence factors.

The fourth common factor mainly includes the key technology system integration degree of prefabricated building, technical personnel allocation and training, prefabricated building design, construction standardization level, and technological innovation. All these factors reflect the technical requirements of prefabricated buildings. These factors are called technical support factors.

The fifth common factor mainly includes financial subsidies, regional economic level, the construction cost of prefabricated buildings, and preinvestment of matched buildings. All these factors reflect the economic factors that influence the construction and popularization of prefabricated buildings. Therefore, this kind of factor is called the economic cost influence factor.

It can be seen from the analysis of the influence factors of each dimension that the market circumstances, policy support, publicity awareness, technical support, and economic cost can reflect most of the information of the original 21 variables. These are the key factors influencing the largescale development of prefabricated buildings in Anhui province. The index system of large-scale promotion of prefabricated buildings in Anhui province is shown in Table 5.

\subsection{Applicability Test of Questionnaire}

2.5.1. Reliability Test. Reliability refers to the index reflecting the true degree of the measured characteristics according to the consistency or stability of the results obtained from the scale. In general, the more consistent the results of the two tests, the smaller the error, and the higher the reliability. In this paper, the SPSS 22.0 software was used to test the reliability of the questionnaire. The Cronbach's alpha value of the overall scale was 0.914 , indicating that the overall reliability of the scale data was good. Cronbach's Alpha values of all latent variables were above 0.75 , indicating good reliability of the questionnaire scale. The reliability statistical scale is shown in Table 6 .

2.5.2. Validity Test. Validity reflects the authenticity and accuracy of the research and generally includes content validity, criterion validity, and structure validity. The SPSS 22.0 software was used to test the validity of the questionnaire. The KMO value of the scale was 0.917 , indicating that 
TABLE 5: Index system of large-scale promotion of prefabricated buildings in Anhui province.

\begin{tabular}{|c|c|}
\hline $\begin{array}{l}\text { Potential variables influence } \\
\text { factors }\end{array}$ & Measured variables \\
\hline Policy support & $\begin{array}{l}\text { PS1: information sharing platform construction; PS2: prefabricated building supervision mechanism; PS3: } \\
\text { prefabricated building production standard system; PS4: prefabricated building industry planning; PS4: } \\
\text { prefabricated construction industry acceptance standard }\end{array}$ \\
\hline Market circumstances & $\begin{array}{l}\text { MC1: consumer buying intention; MC2: assembly building supporting industrial chain; MC3: industrial } \\
\text { support intensity; MC4: developer's development intention }\end{array}$ \\
\hline Propaganda cognitive & $\begin{array}{l}\text { PC1: market recognition; PC2: prefabricated building promotion; PC3: prefabricated building pilot project } \\
\text { demonstration effect; PC4: the cognition and willingness of each participant }\end{array}$ \\
\hline Economic cost & $\begin{array}{c}\text { EC1: regional economic level; EC2: fiscal subsidy; EC3: construction costs of prefabricated buildings; EC4: } \\
\text { logistics and transportation system }\end{array}$ \\
\hline Technical support & $\begin{array}{l}\text { TS1: integration degree of key technology system of prefabricated building; TS2: technical personnel } \\
\text { allocation and training; TS3: standard level of prefabricated building design and construction; TS4: } \\
\text { technology innovation }\end{array}$ \\
\hline
\end{tabular}

TABLE 6: Reliability statistics.

\begin{tabular}{lcc}
\hline Cronbach' $\alpha$ & Cronbach' $\alpha$ based on standardized term & Number of terms \\
\hline 0.914 & 0.915 & 21 \\
\hline
\end{tabular}

the sample was suitable for factor analysis. The significance level of the Bartlett sphericity test was 0.000 , less than 0.05 , and CITC values were both greater than 0.5 , indicating that the validity of the sample data was fine. Combined with the obtained reliability, the sample data can be further analyzed by factor analysis. The sample KMO and Bartlett test results are shown in Table 7.

\section{Construction of Structural Equation Model}

3.1. Establishment of Structural Equation Model. The structural equation model (SEM) is a statistical method that comprehensively characterizes the relationship between observations and latent variables using linear equations [17]. The main ideas are as follows. According to the existing theoretical knowledge, the model about the mapping relationship between variables is obtained through deduction and related assumptions. Then, the observed variable data and the covariance matrix of the data are calculated, and the fitting degree between the variance matrix and the hypothesis model is verified. If the representation result is good, the model is established. Otherwise, the model is modified and iterated. If the model still cannot be fitted after reaching the iterative step, the model will be rebuilt. The model building procedure is as follows:

3.1.1. Model Establishment. Linear equation visualization is used to clarify the hypothesis of causality between observed variables and establish the corresponding model. This includes two parts: measurement model and structure model. The measurement model mainly represents the relationship between observed variables and potential variables. Through this model, potential variables are mapped from observed variables. The structural model represents the relationship between potential variables.
3.1.2. Model Recognition. The purpose of model recognition is to determine whether a unique estimate corresponding to all free (unknown) parameters can be obtained from observed data. The estimation of the SEM model must be exactly recognized or overrecognized model. For the model which cannot be identified, the corresponding structural equation cannot be established and the path coefficient can be solved.

3.1.3. Model Fitting. Model fitting is solved by substituting the specific parameters of the observed variables obtained from sampling and measurement into the structural equation model. It is to carry on the checking calculation estimation to each unknown parameter.

3.1.4. Model Evaluation. The so-called model evaluation is to fit the rationality of unknown parameters obtained during model fitting. If the model fits well, then the modeling is stopped.

3.1.5. Model Modification. There will be unreasonable assumptions in the initial model construction process. By comparing the indexes and standards, the specific reasons for the poor model fitting degree are found and the corresponding hypotheses are deduced, and then the data model is revised. Finally, a model with a good fitting degree is obtained through iteration.

3.1.6. Model Interpretation. The structural equation model is fitted, evaluated, and modified accordingly. After obtaining the resulting model with a good fitting degree, the model is interpreted and analyzed according to the calculated potential variables and path parameters. Finally, the mapping between variables is found. 
TABLE 7: KMO and Bartlett tests.

\begin{tabular}{lcc}
\hline & KMO sampling suitability quantity. & \\
\hline & Last time I read card squared & 0.917 \\
Bartlett's sphericity test & Degrees of freedom & 2367.518 \\
& Significant & 0.210 \\
& 0.000 \\
\hline
\end{tabular}

The structure of the structural equation model is shown in Figure 2.

Path assumption:

H1: prefabricated building policy support factors will have a positive impact on market environmental factors;

$\mathrm{H} 2$ : policy support factors for prefabricated buildings will have a positive impact on economic cost factors;

H3: prefabricated building policy support factors will have a positive impact on technical support factors;

H4: market circumstances factors of prefabricated buildings have a positive impact on propaganda cognition factors;

H5: prefabricated building market environment factors will have a positive impact on technical support factors;

H6: prefabricated building economic cost factors will have a positive impact on market environment factors;

H7: technical support factors of prefabricated buildings have a positive impact on economic cost factors;

H8: technical support factors of prefabricated buildings will have a positive impact on propaganda and cognition factors.

3.2. Establishment of First-Order Model. Amos 21.0 was used to construct a first-order structural equation model. On the basis of literature research and questionnaire survey, the path hypothesis is proved to be reasonable by data analysis. As shown in Figure 3, the path coefficients and data of each measurement model and structural model were tested for violation estimation. Generally, if the normalized structure path regression coefficient of potential variables exceeds 0.95 or there is a negative error variance, it is considered as a violation of the estimate and should be further modified. The fit and fit tests can be carried out only after the model modification results are passed. If it meets the standard requirements, it indicates that the constructed model is wellmatched with the data. According to the fitting results of the first-order structural equation model shown in Tables 6 and 7 , the indexes of the model: absolute fitting index ( $X^{2} / d f$, GFI, AGFI, RMSEA), value-added fitting index (CFI, IFI, TLI), and reduced fitting index (PCFI, PGFI) all meet the standards, indicating that the model is suitable.

The estimated values of each parameter obtained during first-order confirmatory factor analysis of each potential variable are shown in Table 8 . It can be seen that the path coefficients of each direct effect are all valid. The fitting results of the model are shown in Table 9. All indicators are in line with the evaluation criteria.
3.3. Establishment of Second-Order Model. According to the first-order structural equation model shown in Figure 3, path correlation coefficients of all potential variables are highly correlated, and second-order confirmatory factor analysis can be continued. The Amos 21.0 software was used to reinsert the sample data into the newly constructed second-order structural equation model to analyze and verify the correlation between the large-scale promotion of prefabricated buildings and five potential variables. The second-order standardized structural equation model is shown in Figure 4. All indicators are ideal and meet the standard requirements. The second-order model fitting indexes are shown in Tables 10 and 11. The overall fit of the model is good and the fit degree is high. Objective coefficients are generally used to test the existence of higher-order structural equation models. In the model architecture of this paper, taking the first-order model as the target model, it provides a reasonable basis for the establishment of the influencing factor model for the large-scale extension of second-order prefabricated buildings.

The estimated values of each parameter obtained during the second-order confirmatory factor analysis of each potential variable are shown in Table 10, and the path coefficients of each direct effect are all valid. The fitting results of the model are shown in Table 11. All indicators are in line with the evaluation criteria.

\section{Structural Equation Model Analysis}

4.1. First-Order Standardization Model Analysis. The results of fitting indexes of the model are in line with the evaluation criteria. The parameter estimation index $P$ values of potential variables and observed variables all met the requirements $(<0.05)$ can be inferred. All path assumptions in the model are valid. The overall analysis of the model results shown in Figure 5 is as follows:

(1) The structural path coefficients of policy support factor, economic cost factor, market circumstances factor, technical support factor, and publicity and cognition factor in the large-scale promotion model of prefabricated buildings are $0.86,0.71,0.73,0.87$, and 0.68 , respectively. All values are greater than 0.5 . It shows that the potential variables have a significant influence on the large-scale promotion of prefabricated buildings. Starting with these five dimensions, in particular, we should pay more attention to the policy support and technical system construction of prefabricated buildings, so as to rapidly promote the large-scale promotion of prefabricated buildings in Anhui province. 


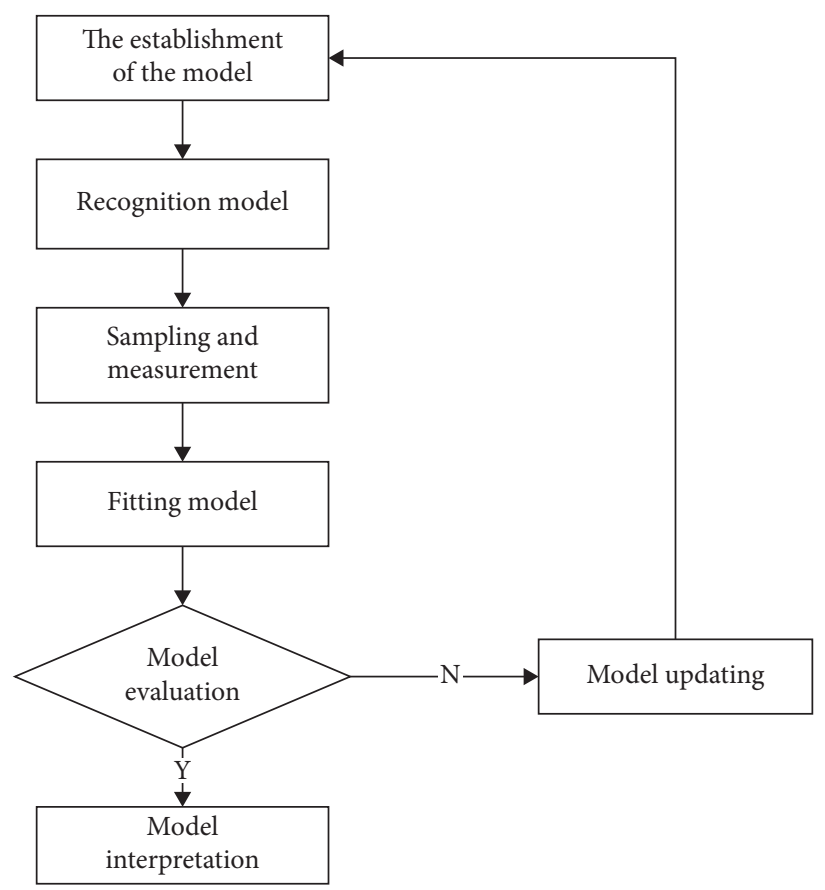

Figure 2: Structural equation model analysis of the basic procedures.

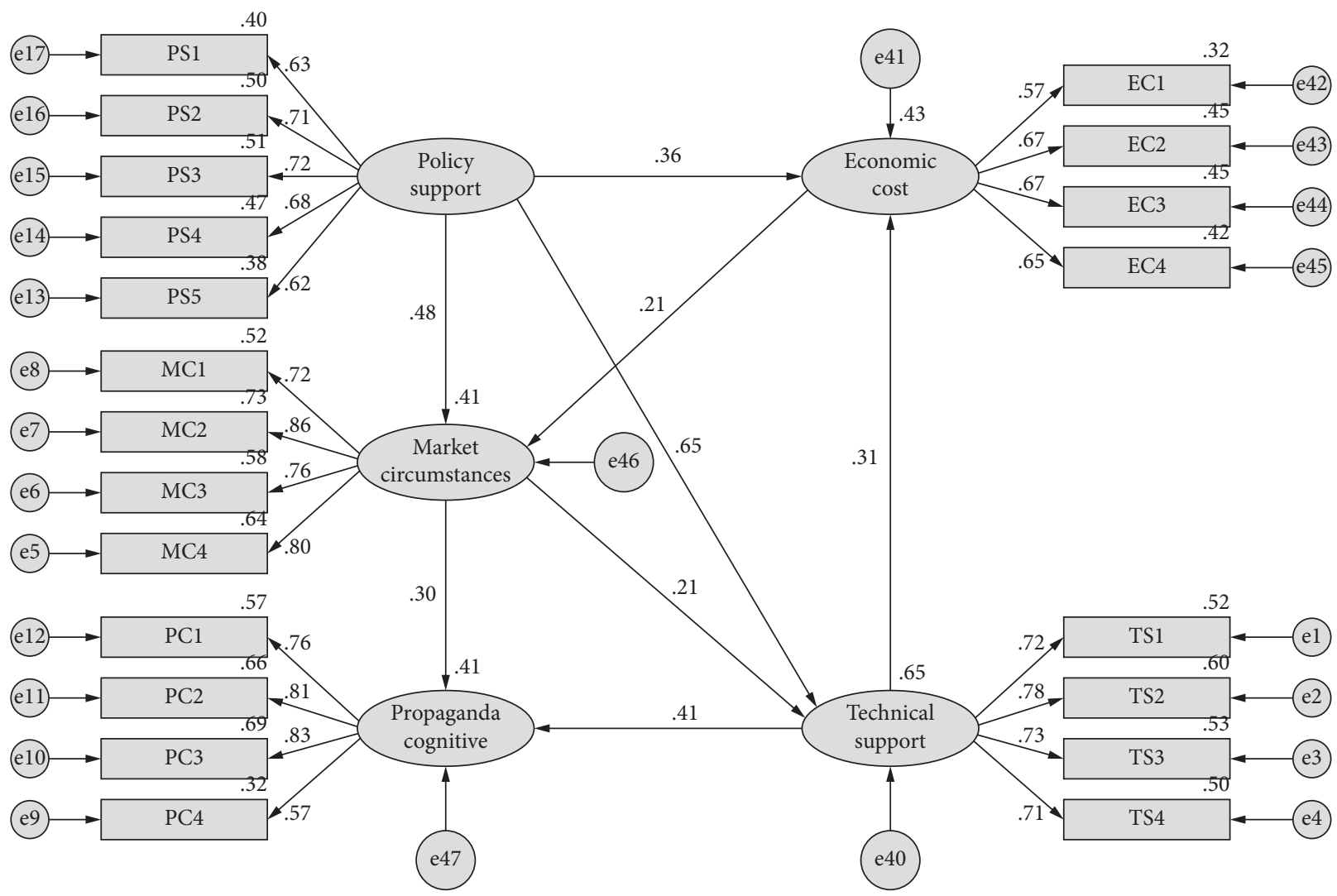

FIGURE 3: Standardized structural equation model of first-order confirmatory factor analysis.

(2) The influence degree of policy support factors on market circumstances factors, economic cost factors, and technical support factors in the large-scale promotion model of prefabricated buildings is 0.48 ,
0.36 , and 0.65 , respectively. A significant positive correlation is observed. It shows that policy support factors have a great influence on market circumstances factors and economic cost factors. For 
TABLE 8: Estimated values of latent variable parameters of the first-order model.

\begin{tabular}{|c|c|c|c|c|c|}
\hline Path & Estimate & S.E. & C.R. & $P$ & Hypothesis verification results \\
\hline Market circumstances <---policy support & 0.529 & 0.114 & 4.627 & $* * *$ & H1 was found \\
\hline Economic cost <---policy support & 0.303 & 0.127 & 2.377 & 0.017 & $\mathrm{H} 2$ was found \\
\hline Technical support <---policy support & 0.706 & 0.114 & 6.218 & $* * *$ & H3 was found \\
\hline Propaganda cognitive <---market circumstances & 0.229 & 0.073 & 3.141 & 0.002 & H4 was found \\
\hline Technical support <---market circumstances & 0.210 & 0.080 & 2.630 & 0.009 & H5 was found \\
\hline Market circumstances <--economic cost & 0.281 & 0.137 & 2.056 & 0.040 & H6 was found \\
\hline Economic cost <---technical support & 0.241 & 0.119 & 2.031 & 0.042 & H7 was found \\
\hline
\end{tabular}

TABLE 9: Evaluation results of first-order model fitting indexes.

\begin{tabular}{lccccccccc}
\hline Fitting index & $X^{2} / d f$ & GFI & AGFI & RMSEA & CFI & IFI & TLI & PCFI & PGFI \\
\hline Evaluation standard & $(1,3)$ & $>0.90$ & $>0.80$ & $<0.08$ & $>0.90$ & $>0.90$ & $>0.90$ & $>0.50$ & $>0.50$ \\
The first-order model & 1.324 & 0.915 & 0.892 & 0.036 & 0.973 & 0.972 & 0.968 & 0.838 & 0.717 \\
Adaptation to judge & Coincident & Coincident & Coincident & Coincident & Coincident & Coincident & Coincident & Coincident & Coincident \\
\hline
\end{tabular}

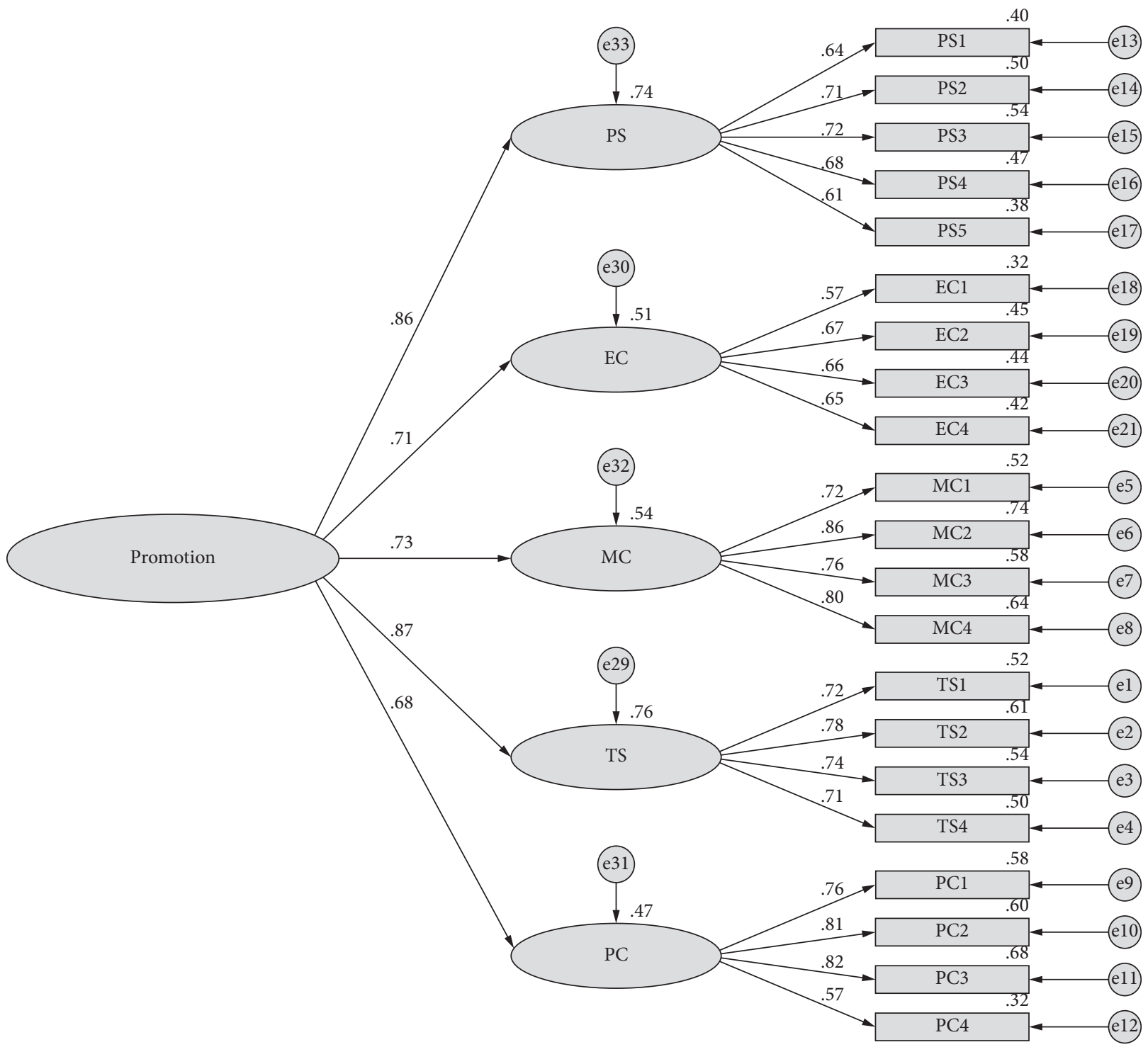

FIGURE 4: Standardized structural equation model of second-order confirmatory factor analysis. 
TABLE 10: Estimated values of latent variable parameters of the second-order model.

\begin{tabular}{|c|c|c|c|c|}
\hline Path & Estimate & S.E. & C.R. & $P$ \\
\hline 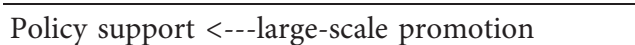 & 1.249 & 0.215 & 5.798 & $* * *$ \\
\hline Economic cost <---large-scale promotion & 0.800 & 0.138 & 5.798 & $* * *$ \\
\hline Market circumstances <---large-scale promotion & 1.098 & 0.154 & 7.137 & $* * *$ \\
\hline Technical support <---large-scale promotion & 1.279 & 0.169 & 7.562 & $* * *$ \\
\hline Propaganda cognitive $<---$ large-scale promotion & 0.781 & 0.130 & 5.999 & $* * *$ \\
\hline
\end{tabular}

TABLE 11: Evaluation results of second-order model fitting index.

\begin{tabular}{lccccccccc}
\hline Fitting index & $X^{2} / d f$ & GFI & AGFI & RMSEA & CFI & IFI & TLI & PCFI & PGFI \\
\hline Evaluation standard & $(1,3)$ & $>0.90$ & $>0.80$ & $<0.08$ & $>0.90$ & $>0.90$ & $>0.90$ & $>0.50$ & $>0.50$ \\
The first-order model & 1.295 & 0.915 & 0.893 & 0.035 & 0.975 & 0.974 & 0.971 & 0.854 & 0.729 \\
Adaptation to judge & Coincident & Coincident & Coincident & Coincident & Coincident & Coincident & Coincident & Coincident & Coincident \\
\hline
\end{tabular}

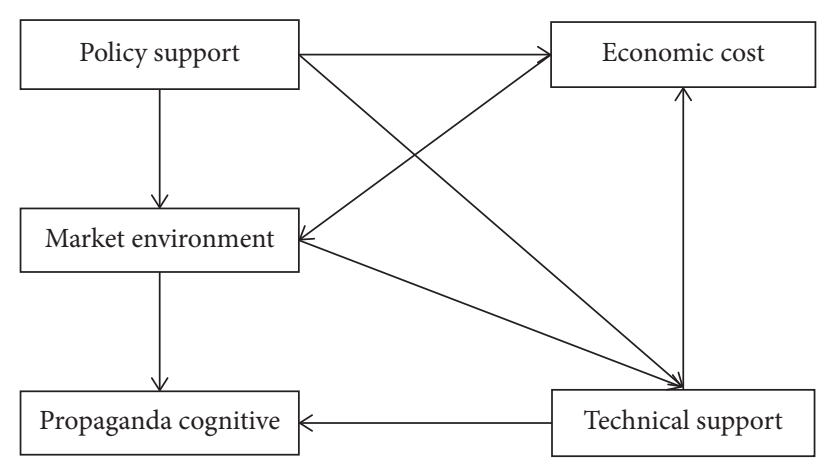

Figure 5: Model of influencing factors for large-scale promotion of prefabricated buildings.

example, the more perfect the prefabricated building promotion policy, the less resistance in the prefabricated building market promotion and prefabricated building investment and development. It is helpful for the construction of prefabricated building technology systems and the large-scale promotion of prefabricated buildings. Key indicators affecting market circumstances, economic cost, and technical support factors among policy factors. It is necessary to increase the support to promote the large-scale promotion of prefabricated buildings indirectly.

(3) In the large-scale promotion model of prefabricated buildings, the influence degree of market circumstances factors on publicity cognition and technical support factors is 0.30 and 0.21 , respectively, showing a significant correlation. Emphasis should be placed on strengthening the willingness of consumers and developers to participate in the promotion of prefabricated buildings, strengthening industrial support, and rapidly promoting the construction of the whole industrial chain. Thus promoting the assembly building market recognition and improving the technical support system. The influence degree of economic cost factor on market circumstances factor is 0.21 , and the path is significant. The introduction of prefabricated buildings is still constrained by high construction costs. This requires the government and other departments to promote the assembly building incentive policies and establish a complete assembly building supporting the industry chain. Thus enhancing the willingness of all participants to participate.

(4) In the large-scale promotion model of prefabricated buildings, the degree of influence of technical support factors on publicity cognition factors and economic cost factors is 0.41 and 0.31 , respectively, and the path is significant. It is necessary to strengthen the training of assembly-building-related talents. The standardization of construction will be improved to provide a complete technical support system for assembly building. Thus, it helps to reduce economic costs and enhance market recognition of prefabricated buildings.

4.2. Analysis of Second-Order Standardization Model. The analysis of each dimension is as follows:

(1) In the policy support dimension of the large-scale promotion model of prefabricated buildings, the impact degree of the production standard system and supervision mechanism of prefabricated buildings is 0.72 and 0.71 , respectively. The establishment of a production standard system and supervision 
mechanism of the prefabricated building is helpful to get through the design, production, and engineering construction of the prefabricated house. It can promote the coordinated development of the whole industry chain and solve the connection problem between the standardized design of prefabricated buildings and the application of standardized components and parts. It also provides strong technical guidance for designers and constructors [18]. In addition, specific dimensions of components and parts can be standardized by specifying them in general, and gradually guides the transformation of customized and small-scale production methods to standardization and socialization. Manufacturing enterprises, design units, and construction enterprises are guided to coordinate and unify the common dimensions of components and parts. We will comprehensively improve the efficiency of industrial production, design, and construction of new buildings. Thus, promote the assembly building industry to standardization, scale, and marketization.

(2) In the dimension of market circumstances of the large-scale promotion model of prefabricated buildings, the influence degree of the supporting industrial chain of prefabricated buildings and the developer's development intention is 0.86 and 0.80 , respectively. At present, Anhui province assembly building intelligent products, logistics transportation, research and development testing, design consulting and vocational training and other industries are relatively weak. The industrial chain is still incomplete. The layout of the prefabricated building industry should be optimized. We will improve the intelligent construction platform system for the whole industrial chain of prefabricated buildings; improve the standardization and intelligentization level of assembly building design; create a whole life cycle industrial chain of construction, including design, production, construction, installation, decoration, and operation and maintenance; and achieve the goal of "standardization, industrialization, integration and intelligentization" of the assembly building industry [19]. At the same time, the project general contracting model is promoted. It takes the lead in implementing the project general contract management mode of integration of design, construction, and component production in government-invested projects. In addition, the general contracting mode of engineering is gradually covered in social investment projects. Increase developer willingness and participate in development and reduce construction costs. These are all conducive to the overall advancement of prefabricated buildings in Anhui Province.

(3) In the publicity cognition dimension of the prefabricated building large-scale promotion model, the influence degree of market recognition, prefabricated building publicity and promotion, and prefabricated building pilot project demonstration effect were $0.76,0.81$, and 0.82 , respectively. The leading role of prefabricated building demonstration projects should be effectively brought into play. The tracking guidance and technical service of the project implementation process should be strengthened. We will promptly review, summarize and popularize appropriate technologies and empirical models, and constantly consolidate and expand demonstration results, intensify publicity and promotion efforts [20], enhance market confidence and recognition of prefabricated buildings, and then promote the highquality development of Anhui province prefabricated buildings.

(4) In the economic cost dimension of the large-scale promotion model of prefabricated buildings, the path coefficients of financial subsidies and construction costs of prefabricated buildings are large. Production, transportation, and installation costs of prefabricated components in prefabricated buildings remain high. The construction cost of prefabricated buildings is high. The government can give some subsidies to the prefabricated building projects undertaken by developers through financial subsidies and other preferential economic policies to encourage the development of prefabricated buildings. This is conducive to the construction cost control of prefabricated buildings to promote their large-scale promotion [21].

(5) In the dimension of technical support of the largescale extension model of prefabricated buildings, the path coefficients of technical personnel allocation and training and the standardization level of prefabricated building design and construction are 0.78 and 0.74 , respectively. The Ministry of Housing and Urban-Rural Development and the other nine departments jointly issued several opinions on speeding up the industrialization development of new buildings, which clearly stated that the talent cultivation should be strengthened. We will accelerate the cultivation of prefabricated construction personnel. Furthermore, improve the theoretical and technical level of construction engineering professionals to carry out professional training for assembly engineers [22]. At the same time, the standardization of prefabricated building design and construction is an effective means to achieve the promotion of prefabricated building. It can effectively improve production speed and labor efficiency, thereby reducing cost and improving economic benefits.

\section{Conclusion}

The model is analyzed by constructing the large-scale extension equation model of prefabricated buildings in Anhui province. The impact of potential variables on the large-scale 
promotion of prefabricated buildings is explored. From the structure path coefficient of each potential variable and the load of each factor, it can be seen that the policy support, market circumstances, publicity awareness, economic cost, and technical support have different degrees of important influence on the large-scale promotion of prefabricated buildings. To promote the development of prefabricated buildings in Anhui province, we should accelerate the establishment of an effective working mechanism for each participant in the industrial chain by means of government leadership and market regulation. Combined with the above analysis results, this paper puts forward the following promotion strategies.

5.1. Improving the Standard and Standard System. The construction administrative departments, construction enterprises, and prefabricated building industry associations in Anhui province should be encouraged to improve the relevant supporting construction methods, technical guidelines, and standard atlas; actively work out the local standards, enterprise standards, and industry standards; and promote the standard with good adaptability and maturity and improve it to the superior standard in time [23]. It is committed to providing the reference standard basis for the whole process of design, production, construction, decoration, and supervision units in the assembly construction industry chain. Thus, the quality and performance of prefabricated buildings can be improved.

5.2. Strengthening the Supervision Mechanism. The prefabricated construction industry should attach great importance to engineering quality and safety supervision issues. At this stage, the main body of supervision is the construction administrative department of governments at all levels. In the future, more attention should be paid to the active role of the main body of social supervision to realize the coordinated supervision mechanism of government supervision, industry self-discipline, and market mechanism [24]. To improve the traditional construction supervision mode, which focuses on prior approval and light on process supervision, the whole life cycle quality traceability responsibility system should be established to implement the quality assurance mechanism, and the early stage through strict market access system should be established to avoid construction quality risk. During the process, strengthen supervision of key nodes, strengthen supervision of construction, and production behaviors of all parties in the industrial chain are followed to ensure quality and safety. Finally, administrative punishment and other measures are taken to supervise illegal acts.

5.3. Increase the Industry Talent Training. There is a shortage of talent in the prefabricated construction industry. The government should cooperate and guide undergraduates and set up vocational colleges for prefabricated buildingrelated majors scientifically and rationally. Each main body of the industrial chain should strengthen the training of relevant management personnel, technical personnel, operation and management personnel, and assembly construction labor workers. Vocational skills training bases should be established. The practical operation ability of applied talents should be cultivated. Prefabricated building training standards and professional skills appraisal system should be established. Transformational learning and training opportunities for some technical and managerial talents should be provided regularly. "Teach students according to their aptitude" should be established for longterm development mechanism of talent training [25].

\subsection{Applying BIM, Internet of Things, and Other Big Data} Technologies. At present, the prefabricated construction market in Anhui province has not established a construction environment suitable for the construction of prefabricated buildings in the Internet of Things, and some construction units have not fully mastered the technical points of BIM and other big data prefabricated construction. Therefore, the big data construction system of prefabricated buildings should be established as soon as possible in accordance with the actual situation of Anhui province, and comprehensive and targeted design specifications should be formulated. In addition, the integration degree of key technology systems of the prefabricated building also needs to be optimized. It is necessary to actively promote the promotion role of cloud computing, Internet of Things, BIM, and other information technologies in the construction of prefabricated projects so that the integration technology of prefabricated parts can play a role and achieve the goal of green construction, intelligent construction, and lean construction of prefabricated building projects. At the same time, actively developing 5G communication technology and developing corresponding operating software to escort the development of Internet of Things, BIM, and other technologies.

5.5. Improving the Policy Subsidy System. Ministry of Housing and Urban-Rural Development's "13th Five-Year" prefabricated building action plan clearly proposed that all localities should formulate prefabricated building promotion mechanisms to meet provincial conditions. Although the Anhui province proposes to implement supporting policies, there is no specific economic incentive and subsidy measures to define the subsidy phase. Subsidies and incentives for prefabricated buildings should be "tailored to the situation". According to the different stages of prefabricated building development to develop incentive standards that can harmonize market development, in the early stage of industrial advancement, all kinds of work need to carry out exploration and learning. In addition, immature management, technology, and cognition lead to the inevitable "learning cost" and high construction cost. Enterprises are afraid of difficulties and need to increase subsidies and incentives [26]. With the continuous development of assembly management and construction technology and the maturity of market cognition, economies of scale have been achieved and construction costs of prefabricated buildings 
are falling. At this point, we should consider reducing the subsidy incentives or stopping them.

This paper uses the structural equation model to analyze the influence factors of the construction scale of the assembly building in Anhui province. Political policy support, market environment, publicity awareness, economic cost, and technology support are five dimensions as the pointcut. The influence of various potential variables on the scale of assembly construction is analyzed. The extent of the influence is from large to small arrangements: technical support, policy support, market environment, economic cost, and public awareness. The corresponding suggestions are made based on the influence of each influencing factor. It provides the theoretical basis for the popularization of assembly building scale in Anhui province, which helps to control the key control. It is expected to provide further interpretation of the construction scale promotion of Anhui province to promote better and faster development of the Anhui assembly building.

\section{Data Availability}

The datasets used and/or analyzed during the current study are available from the corresponding author on reasonable request.

\section{Conflicts of Interest}

The authors declare that they have no conflicts of interest.

\section{Acknowledgments}

The authors disclosed receipt of the following financial support for research, authorship, and/or publication of this article: Anhui University Humanities and Social Sciences Research Project: Research on the Comprehensive Benefits of Prefabricated Buildings (No: SK2018A0568).

\section{References}

[1] W. Chen, "Development and promotion of prefabricated buildings," Journal of henan institute of urban construction, vol. 27, no. 4, pp. 62-66, 2018.

[2] X. Pang, Research on Life-Cycle Cost-Benefit Analysis of Prefabricated Buildings, Qinghai University, Xining, China, 2019.

[3] N. Mao, Cost Analysis and Control Countermeasures of Prefabricated Concrete Building, Fujian Institute of Technology, Fuzhou, China, 2018.

[4] J. Dong, Research on Life-Cycle Cost-Benefit Analysis of Prefabricated Buildings, Beijing Jiaotong University, Beijing, China, 2019.

[5] M. Wang, Life Cycle Cost Analysis and Countermeasures of Prefabricated Buildings, Shenyang Jianzhu University, Shenyang, China, 2017.

[6] J. Shen, Y. Hua, and M. Yuan, "Study on lean cost management of assembly building," Building economy, vol. 40, no. 3, pp. 45-49, 2019.

[7] Y. Zhou, Research on Prefabricated Building Cost Management Based on Lean Theory, Huazhong University of Science and Technology, Wuhan, China, 2019.
[8] M. Wang and Z. Wu, "Incremental cost analysis and countermeasure research of prefabricated concrete building," Construction Economy, vol. 38, no. 1, pp. 15-20, 2017.

[9] Y. Cui, Analysis on the Influencing Factors and Countermeasures of Prefabricated Concrete Building Cost, Shandong Jianzhu University, Jinan, China, 2018.

[10] J. Barlow, P. Childerhouse, D. Gann, S. Hong-Minh, M. Naim, and R. Ozaki, "Choice and delivery in house building: lessons from Japan for UK house builders," Building Research \& Information, vol. 31, no. 2, pp. 134-145, 2003.

[11] R. Bortolini, C. T. Formoso, and D. D. Viana, "Site logistics planning and control for engineer-to-order prefabricated building systems using BIM 4D modeling," Automation in Construction, vol. 98, pp. 248-264, 2019.

[12] J. Hong, G. Q. Shen, Z. Li, B. Zhang, and W. Zhang, "Barriers to promoting prefabricated construction in China: a costbenefit analysis," Journal of Cleaner Production, vol. 172, pp. 649-660, 2018.

[13] D. Lopez and T. M. Froese, "Analysis of costs and benefits of panelized and modular prefabricated homes," Procedia Engineering, vol. 145, pp. 1291-1297, 2016.

[14] B. Johnstona, T. Bulbula, Y. Beliveaua, and R. Wakefield, "An assessment of pictographic instructions derived from a virtual prototype to support construction assembly procedures," Automation in Construction, vol. 64, pp. 36-53, 2016.

[15] M. M. Fard, S. A. Terouhid, C. J. Kibert, and H. Hakim, "Safety concerns related to modular or prefabricated building construction," International Journal for Consumer and Product Safety, vol. 24, no. 1, pp. 14-26, 2017.

[16] M. Arashpour, B. Yu, G. Aranda-Mena, A. B. Hadiashar, R. Hosseini, and P. Kalutara, "Optimizing decisions in advanced manufacturing of prefabricated products: theorizing supply chain configurations in off-site construction," Automation in Construction, vol. 84, pp. 146-153, 2017.

[17] T. jung, AMOS and Research Methods, Chongqing University Press, Chongqing, China, 2009.

[18] L. Zhang and H. Zheng, "Research on obstacles to the development of construction industrialization," Construction Economy, vol. 2, no. 2, pp. 9-13, 2016.

[19] J. Wang, J. Zhao, and Z. Hu, "Thoughts on the present situation of my country's construction industrialization development," China Civil Engineering Journal, vol. 47, no. 4, pp. 301-304, 2017.

[20] Y. Gao, "Singapore prefabricated building development planning and experience reference," Housing Industry, vol. 7, pp. 12-19, 2017.

[21] J. Li, Research on Restricting Factors and Countermeasures of Housing Industrialization Development in China, Chongqing University, Chongqing, China, 2012.

[22] Y. Wang, Q. Liu, and Q. Yang, "Research on the forecast of China's future labor demand," Statistics \& Decisions, vol. 12, no. 12, pp. 87-90, 2015.

[23] Q. Chen, Research on Development Process and Restriction Factors of Prefabricated Building Standard Specification, Huaqiao University, Quanzhou, China, 2019.

[24] Y. Xu, Y. Kong, and M. Zhao, "Research on the Main obstacles and Countermeasures of the development of China's building industrialization," Building Economist, vol. 37, no. 10, pp. 5-9, 2016.

[25] S. Liu, Analysis of the Role of Housing Industrialization in Solving the Problem of Construction Labor Shortage, Dalian University of Technology, Dalian, China, 2015.

[26] G. Ni, X. Jian, J. Wang, Y. Qiao, and B. Cao, "Research on the constraints of China's assembly building industry chain," Building economy, vol. 41, no. 6, pp. 13-18, 2020. 